João Felicio Scárdua, economista, é o secretário de Modernização Administrativa do MEC

\title{
O MEC e a reforma administrativa
}

\section{Um Ministério em processo de transformação}

O atual Ministério da Educação e Cultura tem suas origens no decreto n: 19.402, de 14 de novembro de 1930, quando foi criada "uma Secretaria de Estado com a denominacão de Ministério dos Negócios da Educação e Saúde Pública". A 5 de janeiro do ano seguinte, através do decreto n: 19.560, foi aprovado o regulamento que organizava a "Secretaria de Estado do Ministério da Educação e Saúde Pública", para a qual já haviam sido criados serviços e transferidas repartições, estas pertencentes até então ao Ministério da Justiça e Negócios Interiores, por intermédio dos decretos n. 19.444, de 1. de dezembro, e n. 19.518, de 22 de dezembro de 1930, respectivamente.

Seis anos depois, pela lei n. 378, de 13 de janeiro de 1937, 0 Ministério da Educação e Saúde Pública passou a denominar-se Ministério da Educação e Saúde, no qual a estrutura básica do Departamento Nacional de Educação aparece com uma significativa amplitude, cobrindo praticamente todas as áreas de ensino.

Nove anos após, em 2 de janeiro de 1946 (decreto-lei n. 8.535), processaram-se alterações na estrutura das divisões organizadas em 1937, que passaram à condição de diretorias subordinadas diretamente ao ministro de Estado.

A denominação de Ministério da Educação e Cultura surge em 1953, quase 23 anos depois de sua criação e sete anos após a última alteração organizacional, em decorrência da criação do Ministério da Saúde (lei n: 1920, de 25 de julho de 1953).

Em 1967, com a promulgação do decreto-lei n. 200, de 25 de fevereiro, a área de competência do Ministério da Educação e Cultura foi estabelecida em termos precisos; como conseqüência passaram a integrar a estrutura básica do Ministério todos os estabelecimentos de ensino mantidos pelo Ministério da Agrıcultura (decreto n: 60.731, de 19 de maio de 1967).

Foi iniciada em 1970, a partir das disposições sobre a sua or- 
ganização administrativa contidas no decreto n? 66.967, de 27 de julho, uma profunda reforma estrutural foi conduzida e aprovada, três anos mais tarde, através do decreto n: 72.614 , de 15 de agosto de 1973.

Em 1978, a menos de cinco anos dessa reforma, a estrutura básica do MEC foi novamente alterada, em amplitude e profundidade significativas (decreto n. 81.454, de 17 de março de 1978).

Finalmente, em 25 de março de 1981 (três anos e oito dias depois de aprovada a última reforma de estrutura básica e período durante o qual foram baixados uma portaria ministerial, dispondo sobre a implantação da organização prevista no decreto-lei n? $81.454 / 78$, e cinco leis e três decretos, transformando ou criando unidades não previstas na estrutura básica anteriormente aprovada) o decreto n: 85.843 estabelece que o Ministério da Educação e Cultura "será objeto de ampla reorganização administrativa".

Este breve histórico mostra que os intervaios entre uma e outra alteração de estrutura e organização do MEC têm sido, com uma única exceção, inferiores a sete anos; e que, a partir de seu desmembramento, em 1953, eles assumem valores cada vez menores, alcançando a incrivel marca de três anos para o último intervalo - que se esgotou, inclusive, antes que a implantação da nova estrutura, aprovada em 1978, tivesse sido concluída.

A atual administração do MEC não desconhece esses dados. As reflexões sobre o processo de reorganização em curso têm procurado identificar as suas causas, explicá-las o suficiente e, principalmente, apreender o sentido das forças que têm conduzido esse processo ao longo do tempo - tendo em vista evitar que, em futuro próximo, outra intervenção global sobre a estrutura se torne necessária.

Desse modo, estão na ordem do dia questões como o sentido, o significado, os objetivos, a amplitude e profundidade, e, principalmente, as medidas necessárias para incorporar à vida do MEC os mecanismos necessários para que o processo adquira foros de perpetuidade, nesse caso desobrigando a instituição de constantes violentações à sua ordem normal de vida.

\section{A questão da identidade}

Acima de todas essas questões paira, no entanto, a preocupação com a investigação e a explicação de qual seja, efetivamente, a identidade do MEC. É o conhecimento dessa identidade que irá indicar, para os agentes de modernização administrativa que hoje conduzem esse novo esforço, as respostas a indagacões do tipo: qual é, exatamente, o papel do Ministério da Educação e Cultura e que funções deve ele desempenhar? Como sua ação deve ser desenvolvida e qual a melhor estrutura de divisão e de organização do trabalho para o MEC?

Qualquer solução para questões dessa ordem depende de decisões articuladas, de um lado com relação ao que se poderá entender como sendo a 'identidade do MEC'; de outro, com relacão à racionalidade organizacional a partir da qual aquela identida- 
Esse é o conflito diante do qual se debatem todos os técnicos que trabalham nesse campo de atividades. O que buscar primeiro? A definição de identidade, a partir do que se pode, com segurança, precisar melhor que tipo de divisão do trabalho é adequada ao trato dos recursos institucionais? Ou a racionalidade organizacional e administrativa, que abre caminho para uma reflexão maior sobre a identidade da instituição?

No caso específico do MEC, a questão - e o dilema - tem contornos definidos e, em alguns aspectos, até mesmo graves. Parece não haver dúvidas de que há uma crise de identidade, na qual todos nós estamos mergulhados: apenas potencial, em alguns casos; latente, em outros; em muitos, emergentes; e, pairando aqui e ali, é possível precisar as suas manifestaç̃̃es mais concretas. Por outro lado, decorrência ou causa disso, há evidentes sinais de que a estrutura básica atual não corresponde às reais necessidades das 'missð̋es' que o MEC deve cumprir e nem admite que a gestão dos negócios afetos à pasta possa ser praticada segundo padrôes adequados de eficiência e eficácia.

Voltando um pouco as atenç̃̃es para a década de 1970, verifica-se que o MEC passou por ela praticamente em processo de reforma. Ainda em 1970 foi definida para ele uma nova organização (decreto n: 66.967, de 27 de julho), cuja estrutura correspondente sofreu alteraçôes sancionadas, três anos depois, através do decreto n: 72.614, de 15 de agosto de 1973.

Esse primeiro grande processo de revisão organizacional foi conduzido a partir de duas referências básicas: os dispositivos da reforma do ensino (Diretrizes e Bases da Educação Nacional, lei n. 4024, de 20 de dezembro de 1961) e da reforma administrativa (decreto-lei n. 200, de 27 de fevereiro de 1967); o primeiro dando uma nova dimensão à educação brasileira e o segundo propondo uma nova filosofia e definindo novos princípios sobre os quais a ação administrativa do Estado seria alicerçada.

A proposta de estrutura aprovada guardava relação com esses mandamentos - não tão recentes, mas com peso suficiente para orientar a busca de uma flexibilidade e leveza suficientemente compatíveis.

Mal concluídos os trabalhos de elaboração das normas que regulariam o funcionamento dessa nova estrutura, outra vez entrou o Ministério em processo de reforma, já não mais buscando uma adequação funcional (segundo objetivos e competências definidas em leis ou planos), senão uma adequação puramente administrativa, contingenciada a partir dos regramentos interpostos pelo DASP ao definir e regulamentar o novo Plano de Classificação de Cargos no serviço público federal.

A reestruturação iniciada em 1970 e concluída em 1973 fo definida dentro de padrões elásticos, permitindo, a partir de uma configuração geral, arranjos os mais variados, tanto no tempo como no espaço, tanto no permanente quanto no conjuntural obedecendo, em linhas gerais, aos postulados da legislação de ensino e da reforma administrativa. No entanto, antes mesmo que testes e avaliaç̃es pudessem ser feitos, tornou-se imperiosa, a partir de 1974, a revisão daqueles padrões, de tal forma que a es- 
trutura pudesse habilitar-se aos cargos e funções do Plano de Classificação de Cargos - e, isso, necessariamente, sob pena de que a competitividade do Ministério diante dos processos de recrutamento e manutenção de pessoal ficasse seriamente comprometida ou irremediavelmente prejudicada.

O período 74/78 é marcado por estudos e negociaç̃es profundamente dirigidas pela busca de soluções que pudessem satisfazer às necessidades de manutenção, e em alguns casos de expansão, de seu quadro de pessoal. As preocupaç̃̃es com a funcionalidade e racionalidade deixaram de presidir as decisões, cedendo lugar à busca de arranjos estruturais capazes de suprir a grande necessidade de renovação e atualização de quadros de pessoal altamente qualificado.

É nesse período que, sem capacidade de recrutamento dentro das regras de jogo estabelecidas em 73/74 ( estrutura leve e flexível, de um lado, e rígidas regras para provimento de cargos, de outro), começaram a ser criados mecanismos os mais variados de recrutamento (tabelas especiais, contratações através de convênios e outros menos importantes).

O período seguinte $(79 / 80)$ foi marcado por uma radical mudança de prioridades: a preponderância dos debates desloca-se do campo das aç̃̃es educativas para o das aç̃es culturais e do campo das aç̃̃es escolares para o das aç̃es comunitárias - sem que a cultura organizacional do MEC estivesse preparada para isso.

Nesse sentido, é suficiente observar que o III Plano Setorial de Educação, Cultura e Desporto (III PSECD), estabelecido para vigir no período 1980/1985, é uma proposta de cunho e conteúdo totalmente diversos daqueles com os quais o Ministério conviveu nos dez anos anteriores - todos eles de caráter centralizador, diretivo e orientado para ações através dos mecanismos convencionais e conservadores. Instala-se, nesse momento, um hiato entre o 'discurso' e o 'recurso': de um lado, um Plano que contém as sementes de um processo educativo atrelado ao cultural, lançadas para uma sociedade colocada diante de um processo de abertura política; e, de outro, uma estrutura em crise de identidade funcional e administrativa, presa a valores do passado e a contingenciamentos normativos decorrentes de uma postura administrativa centralizada, meritocrática e autoritária, reguladora de praticamente todos os aspectos que regem a vida no serviço público federal.

\section{A procura de uma política educacional, culturale desportiva}

A ação governamental no setor tem sido caracterizada pela ausência do que se poderia chamar de uma 'política educacional deliberada', sustentada por uma doutrina claramente definida para a construção de uma sociedade desejável (futura), e por uma teoria aplicável a uma realidade (histórica e atual) conhecida, comprome-
tida e explicada.

Pode-se argumentar que a estruturação de um sistema de idéias criticamente formuladas, e apoiadas no dado empírico da 
realidade histórica, econômica e cultural, não foi ainda definido exatamente pelo fato de faltar a perspectiva histórica e os elementos de julgamento que permitiriam conhecê-las e sistematizá-las em um modelo explicável por uma teoria; faltando a teoria, a argumentação logo justificará a ausência daquela política e, por conseguinte, a ausência de uma ação estrategicamente disposta ao longo do tempo e a partir da qual a fixação de prioridades assuma contornos inteligíveis.

No momento em que se pretende empreender novo esforço de desenvolvimento institucional no campo das açסes educativas, culturais e desportivas, há que se considerar duas questőes, de fundamental importância. A primeira diz respeito ao fato de que a falta dessa política tem obrigado o Ministério da Educação e Cultura a atuar sobre as grandes questð̋es de educação brasileira de forma apenas periférica, acessória, nunca descendo ao fundo dos problemas, freqüentemente atuando sobre os efeitos e não sobre as suas causas, na maior parte das vezes ignorando olimpicamente os interesses dos grupos que atuam no setor ou então postando-se à margem de legítimas manifestaçס̃es de aspiraçð̋es nacionais. A essa postura a-crítica, contrapõe ou aceita um centralismo normativo excessivo e desgastante, exigente de controles, limitador da criatividade e inibidor da inovação; adota, talvez ingenuamente, todo um arsenal de técnicas de planejamento, como forma de superar os entraves decorrentes dessa postura a-crítica, e assiste, impotente, ao crescimento de uma tecno-burocracia que acaba por justificarse por si própria; e, por fim, à falta de um conhecimento crítico acumulado e testado e mergulhando dentro de uma máquina administrativa pesada, lenta e cega, subjuga-se a influências teóricas praticadas em outras culturas, de outras histórias. Essa prática pode ser constatada a partir de uma análise, superficial mesmo, de todo o arcabouço normativo que rege a vida do ensino no país; ou de uma avaliação sumária dos planos, programas e projetos - a maior parte deles ditos prioritários - que dominaram o cenário das aç̃̃es do MEC nos últimos dez ou quinze anos; ou, então, da crítica aos fundamentos teóricos que justificaram as chamadas leis de reforma do ensino superior (1968) ou do ensino de $1^{\circ}$ e $2^{\circ}$. graus (1971).

A segunda daquelas duas questőes fundamentais mencionadas, diz respeito ao fato de que é chegada a hora de debruçar-se o MEC na busca de fundamentos teóricos sobre os quais possa formular, para o governo e para a sociedade, uma política educacional deliberada, prioritária. Sob pena, inclusive, de ver-se mais à margem, ainda, das grandes decisర̃es nacionais sobre educação - na medida em que o projeto de abertura política em curso produza os seus resultados e que a sociedade brasileira, já bem mais adulta, arme-se com os instrumentos adequados para compartilhar do exercício do poder. Nesse momento, é fundamental que as preocupações do Ministério estejam orientadas para a busca do conhecimento crítico da realidade brasileira, sobre o qual seria a ela aplicável; cer, pelo menos, os parâmetros gerais de uma teortrina, e, sobre esta, uma a partir do que se possa formular uma do profundidade; de tal forma política educacional de larger fixadas, metas estabelecidas, prioridaque estratégidas, recursos alocados; e, por fim, a avaliação e confrontação dos resultados da ação empreendida com os pressupos- 
tos que tenham orientado a formulação da política e o planejamento da ação.

\section{As bases do plano de modernização administrativa}

As considerações anteriores contêm, implícita ou explicitamente, os elementos dominantes que têm constituído, agora, suporte para a implementação de açð̃es orientadas para o desenvolvimento institucional do MEC.

De um lado, o processo de abertura política em marcha, que fatalmente introduzirá, no cenário das negociações intergovernamentais, novos institutos sociais e novos padrőes de relacionamento e integração interinstitucional.

De outro, a evolução do debate sobre a educação brasileira, que exigirá não só um conhecimento mais aprofundado sobre as reais demandas nacionais por educação, como também um pacto político-administrativo "capaz de assegurar uma consistência e continuidade de ação até agora à mercê de contingências absolutamente fortuitas ou ingênuas.

No entanto, outras consideraç̃̃es deverão ser levadas em conta, sob pena de que a ação se perca em planos acima da realidade do próprio Ministério. nistério.

Pelo menos oito questões de natureza complexa afetam o Mi-

Em primeiro lugar, destaca-se a ausência de um assessoramento de alto nível, de caráter institucional, e que suporte as tomadas de decisão quanto ao futuro curso de ação. A falta de uma política deliberada acabou por introduzir, no cenário das mais altas decisర̃es sobre educação, cultura e desporto, preocupações com questð̃es mais imediatas, incorporando, àquele que seria o nível das reflexర̃es maiores sobre a sociedade brasileira e seu projeto educativo, rotinas de controle sobre decisões do passado. A visão de futuro foi toldada de tal forma que os órgãos de assessoramento superior não oferecem, hoje, o respaldo necessário para que se possa projetar o impacto de medidas orientadas para o futuro, segundo o tipo de sociedade que se quer construir.

Em segundo lugar, destaca-se a fragilidade da organização e funcionamento de muitas das administrações de sistemas educativos - o que obriga ao MEC assumir encargos visando suprir deficiências estruturais ou funcionais a nível de execução de ações educativas ou de suporte à execução dessas aç̃es. É o caso, por exemplo, das aç̃es relacionadas com a alimentação escolar, a produção e distribuição de material escolar e didático, o treinamento de instrutores e a preparação de pessoal para formação profissional, o planejamento de construções escolares, o estímulo à implantação da indústria nacional de cinema, a construção e equipamento de prédios escolares, etc. Ações essas que, no fundo, acabam por desviar as atenções do MEC para atividades puramente instrumen-
tais.

Decorrente disso, um terceiro aspecto se sobressai: trata-se da agregação, à estrutura do MEC, de órgãos e mecanismos constituídos sob diferentes formas de organização jurídica e administra- 
tiva, exigindo a manutenção de complexas atividades de controle e de supervisão, e criando, por outro lado, situações altamente diferenciadas, seja no que se refere à política de pessoal ou à sistemática operacional adotada.

Uma quarta questão, também decorrente, diz respeito à legislação exaustiva e detalhística que regula o exercício de atividades fins e meios, freqüentemente elaborada não como orientadora ou ordenadora da vida das instituiçőes, unidades ou processos, mas como disciplinadora de aspectos particulares da administração ou da vida acadêmica. É essa mesma legislação que impede ou dificulta a criação de soluções locais, apropriadas às peculiaridades de cada situação.

Em quinto lugar, observa-se nítida deterioração na composição dos quadros de pessoal dos orgãos da administração direta e autárquica. As dificuldades de reposição desses quadros, dentro de padrões cada vez mais exigentes, torna-se cada dia mais difícil seja pelos níveis de remuneração oferecidos, seja pelo desalento que preside as relações entre os servidores recrutados pelo sistema e aqueles recrutados através de esquemas paralelos. Se, por um lado, a convivência com esse tipo de expediente tem permitido superar os entraves interpostos ao recrutamento regular, por outro tem trazido para dentro das organizações um contingente de profissionais sem maiores compromissos com a cultura organizacional estabelecida.

Outro aspecto a considerar diz respeito à ausência do que se poderia chamar de 'verdade orçamentária'. O tratamento dado às questões de planejamento de recursos tem transformado o orçamento do Ministério em uma peça de retórica. As dotaç̃̃es iniciais mal chegam a suportar os encargos até o final do primeiro semestre - obrigando as administrações à negociação contínua de recursos extra-orçamentários. 0 desgaste de energia é violento e o descrédito acaba por tomar conta de todos os ânimos. As atividades de planejamento esgotam-se na constante reprogramação de déficits, e poucas são as ações realmente novas que podem ser implementadas; a par disso, prevalece constante insegurança quanto à sua continuidade, freqüentemente interrompida ou truncada. Na verdade, a quase totalidade das energias vem sendo empregada apenas na manutenção de atividades rotineiras e tradicionais.

Em sétimo lugar, destacam-se os problemas de planejamento e coordenação, em tudo e por tudo afetados por todos os outros contingenciamentos relacionados anteriormente. De fato, a complexidade da estrutura e organização do MEC tornou dominante, na área de planejamento, a preocupação com o controle - perdendose a perspectiva de objetivos e de futuro.

E, por último, destaca-se a falta de dados sistematicamente dispostos e armazenados, e, em conseqüência, a falta de informacões confiáveis, analisadas e interpretadas - de tal forma que parâmetros possam ser estabelecidos e a avaliação realizada sobre os resultados da ação planejada.

Questões menores poderiam ser relacionadas; no entanto, o planejamento da ação administrativa está sendo orientado para esses oito alvos; ora intervindo-se sobre estruturas e processos; ora 
estimulando-se a reflexão para a mudança; por último, tentando-se induzir essa reflexão e mudança.

\section{Linhas gerais de ação}

A partir do início do corrente ano, e especialmente depois da aprovação do decreto n: 85.843 , de 25 de março, as aç̃̃es foram deflagradas em várias frentes

$\mathrm{Na}$ área de planejamento, vem se buscando a concepção de soluções globais, de nível estratégico, que possam apoiar a realização de três grandes movimentos: o primeiro, voltado para dentro do próprio MEC, visando simplificar sua estrutura e racionalizar métodos e processos de operação; o segundo, voltado para fora, buscando a descentralização e regionalização do planejamento e da execução das aç̃̃es do MEC; finalmente, o terceiro movimento, resultante dos dois primeiros, voltado para reposicionar o Ministério como órgão de formulação da política, de definição da estratégia de ação política e de planejamento governamental para o setor.

$\mathrm{Na}$ área de macroorganização, vêm-se empreendendo esforços no sentido de rever a função, os objetivos e a estrutura de cada unidade da estrutura básica do MEC, da administração direta ou indireta. Busca-se, com isto, uma maior consistência estrutural e coerência funcional, corrigindo-se os casos de superposição de funções, duplicação de meios para os mesmos fins, conflitos de competência, questões de subordinação e hierarquia.

$\mathrm{Na}$ área de microorganização, desenvolvem-se esforços de sistematizacãa de rotinas, racionalização de métodos e processos, desburocratização de procedimentos, automatização de operações e desenvolvimento de sistemas de informação.

Finalmente, na área de desenvolvimento de recursos humanos, está em curso um grande esforço voltado para a valorização do servidor, visando, de um lado, proporcionar-lhe melhores condiç̃es de trabalho; de outro, oferecer-lhe novas oportunidades de aprimoramento profissional e funcional; e, finalmente, criar, para ele, um ambiente propício ao seu envolvimento e efetiva participação na vida do Ministério.

Os detalhes são irrelevantes. O importante é o registro de que se processa no MEC, hoje, uma verdadeira revolução de organização dos recursos e de comportamento das pessoas. Soluções administrativas inovadoras estão sendo experimentadas; programas de alcance funcional e social estão sendo implementados; sobretudo, uma nova perspectiva está sendo criada na mente de cada servidor - a de um Ministério ágil, dinâmico, eficiente e eficaz. Tal perspectiva não interessa apenas a nós, do MEC, mas a todos os cidadãos desse país; uns responsáveis pelo gigantesco esforço de desenvolvimento que ora empreendemos; outros, mais jovens, preparando-se nas escolas, para assumirem as mesmas responsabilidades numa nação mais desenvolvida, numa sociedade mais
justa.

É com esse propósito que todo esse esforço se faz. Não apenas para o MEC e nem apenas pelo MEC. Mas sobretudo para a educação, a cultura, o desporto e o ensino brasileiros. Em última análise para o projeto de sociedade que todos nós queremos cons- 